\title{
IDENTIFICATION AND HIERARCHICAL STRUCTURE OF CRITICAL SUCCESS FACTORS FOR INNOVATION IN CONSTRUCTION PROJECTS: CHINESE PERSPECTIVE
}

\author{
Hui LIU ${ }^{\mathrm{a}, \mathrm{b}}$, Miroslaw J. SKIBNIEWSKI ${ }^{\mathrm{b}}$, Mengjun WANG $^{\mathrm{a}}$ \\ ${ }^{a}$ Department of Engineering Management, Central South University, Changsha, China, 410075 \\ ${ }^{b}$ Department of Civil and Environmental Engineering, University of Maryland, \\ College Park, MD 20742-3021, USA
}

Received 10 Feb 2014; accepted 09 Jul 2014

\begin{abstract}
This paper identifies 20 critical success factors (CSFs) of innovation in China's construction projects through literature review, a case study and expert interviews. Integrated Structural Modeling (ISM) and MICMAC (Impact Matrix Cross-reference Multiplication Applied to a Classification) analysis were used to hierarchically structure CSFs as well as to analyze their inter-relationships. The dependence and driver power of each factor were also analyzed. By doing this, this paper presents structural clarity and establishes a hierarchical order for prioritization for the decisionmaking. The findings show that most of the CSFs (19 out of 20) have strong inter-relationships. According to the law of vital few and trivial many, $80 \%$ of effects come from $20 \%$ of the causes for many events. This paper suggests that intensive effort should focus on the root source of CSFs: owner's involvement and leadership, top management commitment, and strategic importance of the innovation project. Besides, external support, which is beyond the innovation project network, plays an important role in the success of innovation in China's construction projects.
\end{abstract}

Keywords: China, critical success factors, construction innovation, integrated structural modeling.

\section{Introduction}

At present, China is in a rapid development period of industrialization, modernization, and urbanization. In accordance with that, the scale of investment for infrastructure is increasing, and it requires innovation to support the development. Moreover, the innovation-driven development in the construction industry has been prioritized in the China's National Twelfth Five-Year Science and Technology Plan, released by Ministry of Science and Technology (MOST) in 2011. The development of construction innovation is expected to facilitate the national capacity of independent innovation. However, the innovation performance of construction industry, especially China's, with respect to productivity, quality, and product functionality has been relatively poor in comparison with other industries (Bosch-Sijtsema, Postma 2009; Slaughter 1998). Furthermore, innovation has been taken as the key factor contributing to the higher productivity, better efficiency and competitiveness in construction project settings (Allen Consulting Group 2010). Therefore, to a large extent, the desperate demand for innovation has generated bottlenecks in the development of China's construction productivity (Ghoddousi, Hosseini 2012).
Innovation, whether technical or not, is complex, dynamic and non-linear (Ozorhon 2013). Within the construction industry, the definition provided by Slaughter (1998) is broadly accepted by participants and academics (Blayse, Manley 2004). She defines innovation as the "actual use of a nontrivial change and improvement in a process, product, or system that is novel to the institution developing the change" (Slaughter 1998, 2000). Construction is a diverse, project-based industry (Ozorhon 2013). The project base nature of construction industry makes every project unique (Veshosky 1998), thus there is significant opportunity and tendency for innovative behaviour (Kulatunga et al. 2006), which, most of the time, tends to happen at the project level (Ozorhon 2013; Winch 2003; Widén et al. 2014). In construction settings, much of the innovation is co-developed with other project participants, such as clients, designers, contractors, subcontractors, suppliers, and consultants, each of which has a different role in the innovation process (Ozorhon 2013).

Literature exploring the process of construction innovation once considered innovation is the responsibility of individual firms (Gann, Salter 2000; Ozorhon et al. 2014). Nevertheless, in the recent era, researchers increasingly emphasize the importance of interfirm coop-

Corresponding author: Hui Liu

E-mail: tumeier1987@hotmail.com 
eration relationships and networks in innovation projects (Holmen et al. 2005; Rothwell 1992; Slaughter 1998), among which Nam and Tatum $(1992,1997)$ emphasize the importance of vertical integration in construction innovation. Ozorhon et al. (2014) also conclude that integration and leadership are two important enablers of innovation in construction. Furthermore, Blayse and Manley (2004) claim that tighter "couplings" among firms and individuals involved in construction projects are likely to be more supportive of innovation. This idea is further strengthened by Miozzo and Dewick (2004) who call for stronger inter-organizational cooperation as a way of enhancing construction innovation. However, the adversarial relations among the numerous participants specializing in different fields of projects have led to the lack of cooperation. So far, the lack of continuous and stable cooperation among participants has been taken as the main reason for the low level of innovation performance of the construction industry (Barlow, Jashapara 1998; Holmen et al. 2005). Hence, exploring the CSFs for cooperation in construction projects with emphasis on innovation is necessary.

This present study focuses on identifying and hierarchically structuring the CSFs of innovation in China's construction projects. Literature review, a case study and expert interviews were used to identify the CSFs. Integrated Structural Modeling (ISM) and MICMAC (Impact Matrix Cross-reference Multiplication Applied to a Classification) analysis were applied to bring structural clarity and establish a hierarchical order for prioritization for the decision-making. The findings can help participants involved in construction projects to improve their understanding in planning and implementing innovation. Projects that have already been embarked upon or are coming should take advantage of it to accelerate excellence in performance.

\section{Identification of CSFs for innovation in China's construction projects}

\subsection{Review of CSFs for construction innovation}

Innovation has a context sensitive nature (Ozorhon 2013), thus, the success or failure of innovation is influenced by a whole range of factors which often vary from one organization to another, from one industry to another, and even from one country to another (Jones, Saad 2003; Bröchner, Badenfelt 2011; Akbiyikli et al. 2012). This present study followed three tracks, which include literature review, a case study and expert interviews, to arrive at the CSFs (Sagheer et al. 2009). A comprehensive literature review was proceeded before, during, and following the case study and expert interviews. The relevant literature reviewed includes journal articles, conference papers, reports, books, internet materials etc. A compilation of literature on the innovation in construction projects is shown in Table 1. The case study project, which would be described in the following part, is investigated for a sufficiently long period of time (one year) to draw insights into how to successfully implement innovation in China's construction projects. The selected experts (The detailed information about the selection process and background of experts will be explained in Section 3) were first asked to list as many ideas as possible about the CSFs. According to the results of literature review, case study and expert interviews, a checklist consisting of 26 factors was conducted. Then the checklist was provided to the experts to obtain their opinions on the initial list of factors identified. Associated modifications (agree, disagree, detailed modification advice-add, delete or combine factors etc.) were made according to the experts' advice. For instance, during the first round, there were three pairs of factors gets combined e.g. the efficient allocation of risks and the reasonable distribution of interests were combined into the reasonable allocation of risks and interests; and there were two factors get deleted such as the cooperation intention of partners. Besides, associated modifications in the presentations of some of the factors were made according to the experts' advice. The process was carried forward until all of the experts reached a consensus. To the end, 20 CSFs of construction innovation were identified and they are illustrated hereinafter.

\subsection{Case study}

The case study project, Shuohuang Railway Project (SRP), was identified because it is one of the winners of the National Scientific and Technological Progress Awards. This award is organized every year in China to award the projects that demonstrate best practices, with particular emphasis on innovation. Shuohuang Railway (SR) is designed to connect the Shanxi-South Neimenggu emerging energy base and the Bohai bay emerging port as well as to become the important integrant of the second large corridor of transporting coal from the west to the east of China. The completion of SRP will improve the flexibility of China's railway transportation network, and eventually will make important contributions to the execution of China's energy strategy and accelerate the development of the national economy. The geographical location of SR is shown in Figure 1.

The overall length of SR is about 367 miles. The long length of this project and the complicated geology

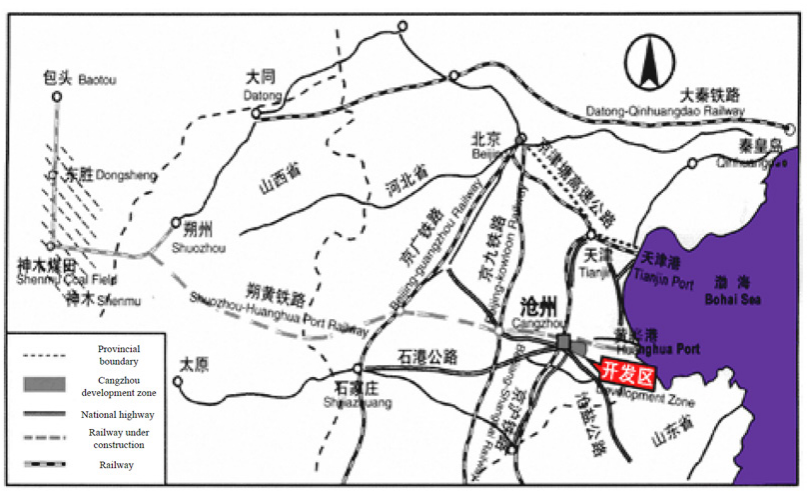

Fig. 1. Geographical location of Shuohuang Railway 


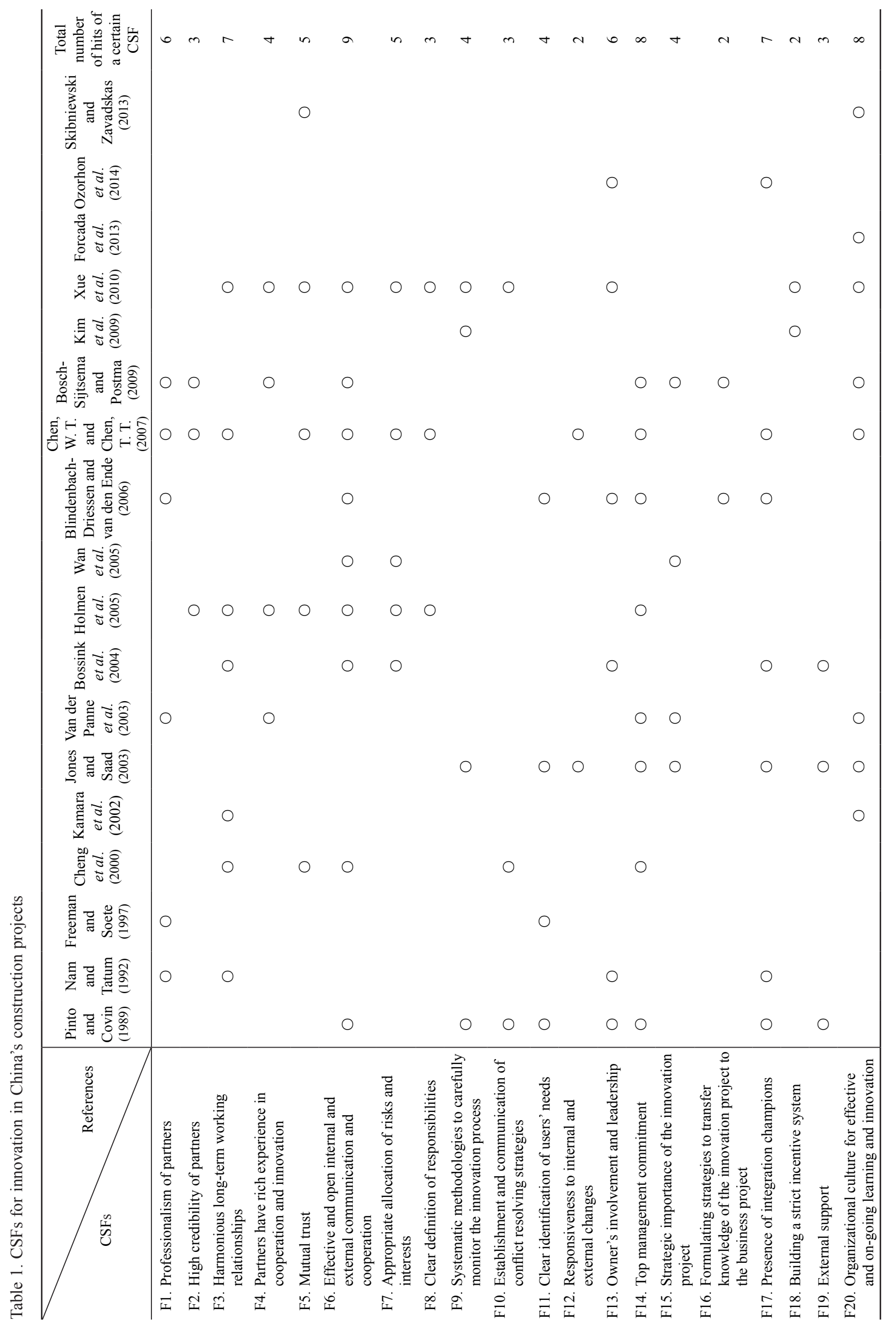


along with the tight project schedule etc. make the construction process of SR have to take advantage of the innovative skills and products. In fact, many innovations that helped to overcome the obstacles faced by this project were introduced. Shuohuang Railway Corporation (SRC) (the owner of the project) organized many relevant experts to focus on doing the research on the railway subgrade design under the condition of special soil. The achievements were successfully implemented in the project including Two Steps a Membrane Geotextile Construction Technology for Salinization Roadbed, Group C Packing Improvement Technology, the New Soft Foundation Treatment Technology and the New Coastal Embankment Construction Technology etc. SRP contains 77 tunnels, among which the Changliangshan tunnel is the longest, 12781.5 meters in total, which brought great challenge for the construction process. To solve this problem, under the administration of SRC, the participants of the innovation network in this project worked collaboratively to tackle key technical problems and formed the comprehensive construction technique for particularly long double-track tunnel under complex geological conditions. Besides, essential problems concerning to the influence from the construction of SRP to the environment were alleviated by the development and application of the environmentally friendly engineering technologies. However, the construction innovation process of this project is not free of challenges. The primary one is the inexperience of workforce and the reluctance of the contractors. Another problem is that the research and development of the technologies required by the construction of SRP is difficult and high-standard, which need the collaborative effort from various players such as research institutes, universities, suppliers, designers, contractors etc. This means that how to effectively and efficiently manage the innovationbased cooperation is the key to the success of this project.

The innovation experience in this case study project was investigated for a sufficiently long period of time (one year) accompanied with several semi-structured interviews with the key stakeholders involved. Other sources of evidence, such as the project documents, were also analysed to gain insights into how to successfully implement construction innovation. The brief introduc- tion of the case study project is shown in Table 2. It is shown that the successful experience of construction innovation of SRP can be concluded into three aspects in terms of the construction of strategic cooperation relationship, the management of the cooperation process and the implementation of construction innovation, which is in line with the findings coming from the above mentioned literature review and expert interviews as well as validate the CSFs identified.

\section{(1) The construction of strategic cooperation relationship}

Partnering provides the basis for the project participants to adopt a win-win approach to solve problems and foster synergistic teamwork (Ozorhon 2013). The partner companies should not only intend to cooperate at the project level, but also own the long term strategic cooperation expectations. SRC as the owner of the project holds a harmonious long-term relationship with a great number of design companies, research institutes, consultation companies and universities alike. All of the partners have good reputation, most of them have rich collaborative working experience before, and have sound working relationships with their former partners, which pave the way for successful innovation in the project.

\section{(2) The management of the cooperation process}

Strategic partnering has helped to ensure the mutual trust among the participants in the innovation network, however, there still needs contractual arrangements to smooth the management process of innovation project. SRP applied a whole set of complete governance measures to insure the success of the project. For instance, all of the participants of the innovation project sign a detailed contract which can fairly and clearly allocate the risks, interests, responsibilities and conflict resolving strategies. The draft, discussion and amendment of the contract text for SRP have been through a long time. The owner organized several discussions among all of the participants of the innovation network to reach the consensus on the cooperative innovation contract. Based on the whole life cycle management method, this project adopted the information network management system to guarantee the internal and external effective communication as well as to monitor the whole process of innovation.

Table 2. Introduction of the case study project

\begin{tabular}{lll}
\hline Project name & Duration & \multicolumn{1}{c}{ Budget } \\
$\begin{array}{l}\text { Shuohuang } \\
\text { Railway } \\
\text { Project }\end{array}$ & 82 months $\$ 2.5$ billion & $\begin{array}{l}\text { To become the important integrant of the second large corridor of transporting coal } \\
\text { from the west to the east of China. The designed transportation capacity of SRP } \\
\text { was } 100 \text { million ton per year (the transportation capacity of SR is now up to 350 } \\
\text { million ton per year after another three years' expansion and renovation thereafter) }\end{array}$ \\
& $\begin{array}{l}\text { Numerous technological or non-technological innovation achievements were achieved. The project was } \\
\text { completed 14 months ahead of schedule, with \$0.44 billion below projected costs. 53 items of new technologies, } \\
\text { processes, materials and machines were adopted during the construction of the project. The project received } \\
\text { plenty of rewards for outstanding construction innovation. For example, it is the winner of the National } \\
\text { Scientific and Technological Progress Awards, National Quality Project Rewards, and Ministry of Railway } \\
\text { Quality Project Rewards etc. Besides it was honored as the National Environmental Friendly Project }\end{array}$ \\
\hline
\end{tabular}




\section{(3) The implementation of construction innovation}

The construction of SRP involves a wide range of regions; it had a huge economic and environmental effect on the local areas, so the project received substantial support from both regional and national governments. The owner-led administration mode was adopted in this project. The owner of the project acted as the main financial founder, decision maker and beneficiary of the innovation achievements in the innovation project. This administration mode helped streamline the information, knowledge sharing, and communication. Its application effectively reduced the risks and conflicts that occurred during the process of the project. Innovation was given strategic importance in this project, which dramatically facilitated the innovation process. The commitment of top management of owner and contractor ensures the construction innovation with sufficient resource and authority. The construction innovation network of SRP establishes proper culture where learning and innovation can flourish. In this context, the participants of the network can efficiently communicate and sharing information by opening their organizational boundaries. Moreover, strict incentive mechanism, which is shown important for the management of construction innovation, is given emphasize from the inception phase of this project. As SRC underlines that the construction innovation should tightly consider the instant and long term engineering requirements, strategies to ensure the engineering application of innovation is important. Moreover, the CEO of this project's owner played as an integration champion to sponsor the new ideas at the highest level of the organization through using his power to move them along and seizing the opportunity to exploit them.

\subsection{CSFs for construction innovation}

Combining the efforts of literature review, a case study and expert interviews, this paper presents a total of 20 CSFs for the innovation in China's construction projects (Table 1). For each CSF identified the frequency at which it was mentioned among the sampled literature was recorded to show its relative state of being aware of (Chan et al. 2010). A brief summary of these factors is given below.

The Chinese construction industry suffers from low trust, adversarial relationships, poor communication and little cooperation etc., thus, the success of innovation in China's construction projects is based first on the selection of cooperation partners (Radziszewska-Zielina 2010). Due to the adversarial relationships, the first concern during the selection of partners is the partner firms' professionalism and credibility. Professionalism here not only includes the specialized skills and technologies, but also means the treatment of occupational requirements as an enduring set of normative and behavioural expectations (Nam, Tatum 1992; Freeman, Soete 1997). Credibility is based on partner firms' intentions toward relationships, mainly in refraining from opportunism (Bosch-Sijtse- ma, Postma 2009; Chen, W. T., Chen, T. T. 2007). It is confirmed that firms with little experience in performing innovation projects in collaboration with other counterparts have difficulty executing successful innovation projects. Thus, it is important for the partners of innovation networks to possess a history of cooperation and a conventional harmonious partnering relationship (Nam, Tatum 1992; Bosch-Sijtsema, Postma 2009; Meng 2013).

The innovation network in construction projects is a complex system. Due to the technical and logistical interdependences, individuals or organizations in the network have to deal with plenty of complicated interfaces (Holmen et al. 2005; Forcada et al. 2013), which may make corresponding organizational or cultural change occur. In that perspective, mutual trust is the basic prerequisite for effective collaboration (Cheng et al. 2000; Holmen et al. 2005; Xue et al. 2010). In addition, considering the fact that the technological innovation network is a virtual organization, the partners change frequently in light of the variable work, therefore, contractual arrangements, which address the allocation of risks as well as interests and the assignment of responsibilities among the stakeholders, are highly required for pursuing the success of construction innovation. Systematic methodologies to carefully monitor the cooperation and innovation process are necessary, which provide feedbacks on the condition of the processes. In case of conflicts, effective conflict resolving strategies should be ready to address the problems.

Jones and Saad (2003) proposed an innovation model which divides the process of innovation into five stages including identification of the need to innovate, knowledge awareness, choice, planning and implementation. Among which implementation is increasingly treated as the heart of successful innovation. Implementation needs to be linked to the organization's background and culture in order to ensure development of compatibility, evaluation, adaption and modification. Consequently, the implementation of innovation is not only to adopt the new technology but also to combine various efforts from many aspects.

First of all, the network organization of the innovation project should have a clear identification of the users' needs. Nevertheless, the users' needs are not constant, so the organization should have an agile responsiveness to internal and external changes (Cheng, Li 2002; Lee, Yu 2012; Cheng et al. 2012). Moreover, significant difference can be made by owner's involvement and leadership (Bossink 2004; Blindenbach-Driessen, van den Ende 2006; Xue et al. 2010; Ozorhon 2013). The more "demanding" and experienced the client (owner) is, the more likely it is to stimulate innovation in projects it commissions. Owners can act as a catalyst to foster innovation by emphasizing the strategic importance of innovation, exerting pressure on project participants to improve innovation performance, or demanding high standards of work (Ozorhon 2013). The measurement of innovation performance is relatively difficult, which 
makes the initial commitment harder to make. Thus, great faith in innovation projects, especially at the inception stage, is required on the part of top management (Park et al. 2012). Willingness of top management to provide necessary resources and authority for project success is highly needed (Cheng, Li 2002).

Pinto and Covin (1989) claim that construction projects are composed of two kinds of projects, which are business projects and innovation projects. A business project is the project executed by order of a specific client whereas an innovation project aims at innovation and takes place separately from a business project (BoschSijtsema, Postma 2009). Most of the time, an innovation project comes from the instant engineering requirement and eventually serves business projects. Given that, strategies to transfer outcomes of innovation projects to business projects should be established (Dubois, Gadde 2002). The champion theory stemming from the manufacturing industry recognizes three types of champions critical to the success of innovation: technical, business, and executive champions. However, construction projects present significant coordination and integration problems due to the extreme specialization of functions (Nam, Tatum 1992, 1997). For that reason, individuals or organizations that facilitate orchestrating inter-organizational cooperation and learning in construction projects are called integration champions in a more reasonable way (Nam, Tatum 1992, 1997). Additionally, a strict incentive system should be built up to motivate initiatives for innovation in construction projects and encourage the presence of integration champions (Katz 2004; Serpell et al. 2013).

China's construction market is fulfilled with a large number of small and medium-sized enterprises. Most of the construction firms are not capable of producing in an innovative way hitherto. In this context, external support from authorities is in demand, such as funds for using innovative technologies and materials, innovation projects rewards, and funds for pilot innovation projects. Last but not least, culture changes are required to facilitate effective and on-going learning and innovation at both the project and individual firm level. However, these culture changes usually take time for most participants in construction projects due to organization inertia and risks aversion created by the competitive and litigious work environment (Skibniewski, Zavadskas 2013; Zavadskas et al. 2010).

\section{Interpretative structural modeling}

The CSFs studied in this paper are not independent and have multiple effects. Hence, it is cumbersome for the decision makers to trace the actual source of these factors (Gudienè et al. 2013). Furthermore, rather than focusing on the root cause, they often tend to focus on the immediate preceding activity which most of the time is not efficient (Lyer, Sagheer 2010). Therefore, the methodology to break down such a complicated system into more explainable structured multilevel subsystems is highly needed. Linstone et al. (1979) and Lendaris (1980) compared different structuring methods based on their characteristics, and they found that ISM, ELECTRE, SPIN, IMPACT, KSIM, XIMP and QSM are cheap, time-saving, easily understandable, and fully implementable, among which, ISM is most frequently used.

The ISM approach was first proposed by Warfield in 1973. The basic idea of this approach is to use experts' practical experience and knowledge to decompose a complicated system into several simple subsystems and construct a multilevel structural model (Lyer, Sagheer 2010; Azevedo et al. 2013). MICMAC analysis developed between 1972 and 1974 by Duperrin and Godet was applied to complement and extend impressions that experienced users draw from visual analysis of influence structures (Sagheer et al. 2009). This method explores influence and dependency between CSFs and classifies them into separate clusters through analyzing the driver power and dependence power of each CSF (Mandal, Deshmukh 1994). Lyer and Sagheer (2010) and Azevedo et al. (2013) conclude that ISM is capable of modeling a diverse range of complex issues by reviewing past literature on application of ISM. ISM along with MICMAC analysis provides a useful hierarchy of factors whose individual relationships are unambiguous but whose group relationships are too complex to organize intuitively and can help practitioners better understand factor dependencies and prioritize CSFs controlling efforts (Sagheer et al. 2009; Lyer, Sagheer 2010; Azevedo et al. 2013). Therefore, this research attempts to approach this method to hierarchically structure and analyze the CSFs of innovation in China's construction projects to present structural clarity and establish a hierarchical order for prioritization for the decision-making. The seven stages involved in this methodology are as follows:

(1) Define the problem to be solved;

(2) Organize an ISM implementation group - choose a group of experts with relevant knowledge, skills and backgrounds related with the research topic (Azevedo et al. 2013);

(3) Identify and select the elements of the problem as well as describe the logic relationship between the elements and the problem. In this present research, these were pursued by the combining efforts of literature review, case study and expert interviews;

(4) Pairwise compare all the elements to obtain directed relationships between them depending on experts' perceptions and generate an Adjacent Matrix. In this stage, the Delphi technique involving the experts assembled in the second stage was applied to obtain the experts' perception of the directed relationships between the risk factors;

(5) Determine the Reachability Matrix;

(6) Partition the reachability matrix and construct a multilevel structural model;

(7) MICMAC analysis - using dependency and driver power of elements in reachability matrix as co-ordinates (Sagheer et al. 2009). 


\section{Obtaining interrelationships between CSFs}

Validity and reliability are two important issues which can decide the amount of rigor and care practiced in overall research design and hence overall effectiveness of the study (Thakkar et al. 2008). Validity is composed of construct validity, internal validity and external validity (Thakkar et al. 2008; Azevedo et al. 2013). Triangulation is a typical strategy for qualitative researchers to check and establish validity and reliability in their studies (Guion et al. 2011). It includes data, investigator, methodological, environmental, and theory triangulation (Azevedo et al. 2013; Guion et al. 2011). To assure validity and reliability, triangulation was used (Azevedo et al. 2013).

The ISM approach suggests the use of experts' empirical experience and knowledge to identify the contextual relationships among and interactions between the CSFs. The Delphi technique was applied to assist this process by a questionnaire effort. The target experts include industrial practitioners who have extensive hands-on experience in executing innovation management in China's construction projects; and academies that have rich experience in doing research about innovation in the construction field. Twenty first experts were invited by phone or email, while only 10 experts agreed to take part in this research as shown in Table 3 . The total participation rate is $47.6 \%$, which is common and acceptable in construction research and meaningful findings can result when the sample draw uses well-developed selection criteria (Yong, Mustaffa 2012, 2013). These experts were chosen based on the participants list of China Engineering Management Forum. This forum, which is held annually, represents the frontiers of China's engineering management and has a high-standard selection criterion for attendees. Ten experts, representing a wide range of profession including clients, contractors, consultants, suppliers, universities and research institutes, 5 from industry and 5 from academia, were consulted from February 2013 to May 2013. All of the ten experts hold senior management positions in their respective companies or institutions, and have significant experience about innovation projects of over 10 years. Six of them belong to the companies or institutions that to some extent have been involved in the

Table 3. Participation rate (in percentage) by type of role in construction industry

\begin{tabular}{lccc}
\hline $\begin{array}{c}\text { Role in construction } \\
\text { industry }\end{array}$ & Invite & Agreed & $\begin{array}{c}\text { Participation } \\
\text { rate } \%\end{array}$ \\
\hline Government & 1 & 0 & 0 \\
Private clients & 3 & 1 & 33.3 \\
Contractors & 4 & 2 & 50 \\
Consultants & 3 & 1 & 33.3 \\
Suppliers & 3 & 1 & 33.3 \\
Universities & 4 & 3 & 75 \\
Research institutes & 3 & 2 & 66.7 \\
Total & 21 & 10 & 47.6 \\
\hline
\end{tabular}

case study project in this present research. To this end, data triangulation was used in this research since the ISM model was developed depending on the contributions of experts from both academia and the construction industry (Azevedo et al. 2013).

Since past literature does not contain any reference about the minimum number of experts to be contacted for their opinion, we can only follow the successful practice of ISM's implementation in project management articles. Sagheer et al. (2009) took advantage of 5 experts' opinions to identify and analyze critical factors influencing standards compliance and their level of influence in developing countries. Lyer and Sagheer (2010) contacted 4 experts for their views to construct ISM model of PPP risks. Azevedo et al. (2013) used 5 experts to identify and rank a set of performance measures based on the approach of interpretative structural modeling. Thakkar et al. (2008) claimed that usually a number between 4 and 10 works well when theoretical saturation is reached.

According to the above-mentioned successful application of ISM approach in the previous studies, we consider our sample (selected based on a purpose sampling) adequate enough to offer external validity. Nevertheless, the extent of generalization should be confined to the Chinese context and specific to innovation in the construction field (Thakkar et al. 2008).

To ensure construct validity, the CSFs proposed in this present research were derived from a thorough literature review in the area of innovation in construction and the insights drawn from the selected case study combining the effort of interviewing experts. A questionnaire was administered to each expert to collect data about the interrelationships between CSFs (see Appendix). In order to achieve internal validity and support experts during the process of the Delphi technique, the researchers initially briefed the experts involved about the study objective and the definition of each CSF. The detailed process was explained to ensure that the experts concentrate on the direct relationships between each pair of CSFs.

\subsection{Forming adjacency matrix of CSFs}

To identify the interacting position of each factor, a contextual relationship of "leads to" was chosen as a focus. Using the framework in Appendix to collect data, experts were asked to identify the extent to which one factor leads to another. The questions used to ask experts contain the existence of a "leads to" relationship between any two factors (Factor $i$ and Factor $j$ ) and the relevant direction of the relation (Azevedo et al. 2013).

We then transformed the result obtained from the questionnaire into a 20-order matrix called Adjacency Matrix (A) in accordance with the following rule.

If factor $i$ leads to factor $j$, then $A(i, j)=1$, or $A(i, j)=0(1 \leq i \leq 20,1 \leq j \leq 20)$.

$\mathrm{A}$ is used to describe the reachability (logical relationship) between factors in the system through one unit length. The mean of each pairwise comparison between 
any two factors was calculated. Mean values of 0 or 1 indicate perfect agreement among all the respondents while mean values lying between 0 and 1 would indicate variance of opinion among the respondents. After obtaining the initial individual responses, values for 303 pairwise comparisons out of 380 (400 minus 20 self-comparisons) had a mean of 0 or 1 . According to the Delphi technique, these remaining 77 comparisons were returned to the experts. The level of differences in opinion for each response was described to the experts. They were asked to revise their answers according to the replies from other members of the expert panel. Consequently, 43 more responses had a mean of 0 or 1 after the second round. The Delphi process was carried forward, 21 more pair comparisons reached consensus during the third round. Hence, there were 367 pairwise comparisons in total had a value of 0 or 1 . Since only 13 responses (3\% of 380 ) were left, to cut short, the majority opinion was taken for the remaining ones (Lyer, Sagheer 2010).To the end, the Adjacency Matrix (A) was achieved. It is shown in Table 4.

\subsection{Forming reachability matrix of CSFs}

As a next step, the Reachability Matrix (R), which indicates both the direct and indirect effects of a factor on all other factors, is generated. The basic assumption for contextual relationships made by ISM is transitivity. It means if $F_{i}$ can reach $F_{j}$ through the access of one-unit length, meanwhile, $F_{j}$ can reach $F_{k}$ through one-unit-length passage, then $F_{i}$ could reach $F_{k}$ through the passage of two units length instead (Azevedo et al. 2013). In light of this feature, $R$ can be achieved by the following formulas:

$$
\begin{gathered}
A_{r}=A^{r} ; \\
A_{1} \neq A_{2} \neq \cdots \neq A_{r-1}=A_{r} ; \\
R=A_{r-1}=A^{r-1} .
\end{gathered}
$$

Among which, $2 \leq r \leq 21$. In addition, the matrix operation in the abovementioned formulas is Boolean algebraic operation. As a result, $R$ indicating the relationship between factors in binary form is presented in Table 5 .

\section{Hierarchical structuring of CSFs}

\subsection{Partitioning the reachability matrix}

$R$ obtained above was then partitioned by deriving the reachability set $\left(R\left(\mathrm{~F}_{\mathrm{i}}\right)\right)$ and antecedent set $\left(A\left(\mathrm{~F}_{\mathrm{i}}\right)\right)$ to obtain ISM hierarchy (Lyer, Sagheer 2010). $R\left(\mathrm{~F}_{\mathrm{i}}\right)$ consists of factors corresponding to the cells that is valued 1 in row $\mathrm{i}$, which means upon which (including $i$ ) $\mathrm{F}_{\mathrm{i}}$ has an impact. $A\left(\mathrm{~F}_{\mathrm{i}}\right)$ is composed of factors corresponding to the cells that is valued 1 in column $i$, which means all the factors included have an impact on the factor i. $\mathrm{M}\left(\mathrm{F}_{\mathrm{i}}\right)$ is the intersection of $R\left(\mathrm{~F}_{\mathrm{i}}\right)$ and $A\left(\mathrm{~F}_{\mathrm{j}}\right)$.

For any factor, if $R\left(\mathrm{~F}_{\mathrm{i}}\right)$ is a complete subset of $A\left(\mathrm{~F}_{\mathrm{i}}\right)$, that factor(s) will be taken out and assigned a particular level (Lyer, Sagheer 2010). In the present study, $R\left(\mathrm{~F}_{\mathrm{i}}\right)$ of factors $10,11,12$, and 16 was found to be a complete subset of $A\left(\mathrm{~F}_{\mathrm{i}}\right)$ (Table 6). Therefore, factors 10,11,12, and 16 were taken out from the $R$ and kept at Level I. The iterative process was continued with the remaining factors where the $R\left(\mathrm{~F}_{\mathrm{i}}\right)$ and $A\left(\mathrm{~F}_{\mathrm{i}}\right)$ of remaining factors were determined (Table 7). In the second iteration, the factors $1 \sim 9$, and 17 were taken out and placed at Level II, among which, there were similar situations happen to factors $1 \sim 8$. Given that, through brainstorming and literature review, in order to make the hierarchical model be easy and clear for users to analyze CSFs, we combined factors 1 9 into two clusters: establishment of contract-based partnerships (consists of factors 7 and 8) and trust-based partnerships (includes factors 1 6). This matches recent research result showing that the construction of contract-based partnerships and trust-based partnerships should go hand in hand to achieve the success of innovation in construction project (Hartmann, Fischer 2008). The process was repeated till

Table 4. Adjacency Matrix of critical success factors

\begin{tabular}{cllllllllllllllllllllllll}
\hline $\begin{array}{c}\text { Factors } \\
(i / j)\end{array}$ & 1 & 2 & 3 & 4 & 5 & 6 & 7 & 8 & 9 & 10 & 11 & 12 & 13 & 14 & 15 & 16 & 17 & 18 & 19 & 20 \\
\hline 1 & 1 & 1 & 1 & 0 & 1 & 0 & 0 & 0 & 0 & 0 & 1 & 1 & 0 & 0 & 0 & 1 & 0 & 0 & 0 & 0 \\
2 & 0 & 1 & 1 & 0 & 1 & 0 & 0 & 0 & 0 & 0 & 0 & 0 & 0 & 0 & 0 & 0 & 0 & 0 & 0 & 0 \\
3 & 0 & 0 & 1 & 1 & 1 & 1 & 1 & 1 & 0 & 1 & 1 & 1 & 0 & 0 & 0 & 0 & 0 & 0 & 0 & 0 \\
4 & 1 & 0 & 0 & 1 & 0 & 1 & 1 & 1 & 0 & 1 & 1 & 1 & 0 & 0 & 0 & 1 & 1 & 0 & 0 & 0 \\
5 & 0 & 0 & 1 & 0 & 1 & 1 & 0 & 0 & 0 & 1 & 0 & 0 & 0 & 0 & 0 & 0 & 0 & 0 & 0 & 0 \\
6 & 0 & 0 & 1 & 0 & 1 & 1 & 0 & 0 & 0 & 1 & 0 & 0 & 0 & 0 & 0 & 0 & 0 & 0 & 0 & 0 \\
7 & 0 & 0 & 1 & 0 & 0 & 0 & 1 & 0 & 0 & 1 & 0 & 0 & 0 & 0 & 0 & 0 & 0 & 0 & 0 & 0 \\
8 & 0 & 0 & 1 & 0 & 0 & 0 & 0 & 1 & 0 & 1 & 0 & 0 & 0 & 0 & 0 & 0 & 0 & 0 & 0 & 0 \\
9 & 0 & 0 & 0 & 0 & 0 & 0 & 0 & 0 & 1 & 0 & 0 & 1 & 0 & 0 & 0 & 0 & 0 & 0 & 0 & 0 \\
10 & 0 & 0 & 0 & 0 & 0 & 0 & 0 & 0 & 0 & 1 & 0 & 0 & 0 & 0 & 0 & 0 & 0 & 0 & 0 & 0 \\
11 & 0 & 0 & 0 & 0 & 0 & 0 & 0 & 0 & 0 & 0 & 1 & 1 & 0 & 0 & 0 & 0 & 0 & 0 & 0 & 0 \\
12 & 0 & 0 & 0 & 0 & 0 & 0 & 0 & 0 & 0 & 0 & 1 & 1 & 0 & 0 & 0 & 0 & 0 & 0 & 0 & 0 \\
13 & 0 & 0 & 0 & 0 & 0 & 0 & 0 & 0 & 0 & 1 & 1 & 0 & 1 & 1 & 1 & 0 & 0 & 0 & 0 & 0 \\
14 & 0 & 0 & 0 & 0 & 0 & 0 & 0 & 0 & 0 & 1 & 0 & 0 & 0 & 1 & 1 & 1 & 1 & 0 & 0 & 1 \\
15 & 0 & 0 & 0 & 0 & 0 & 0 & 1 & 1 & 1 & 0 & 0 & 0 & 0 & 1 & 1 & 1 & 1 & 0 & 0 & 0 \\
16 & 0 & 0 & 0 & 0 & 0 & 0 & 0 & 0 & 0 & 0 & 0 & 0 & 0 & 0 & 0 & 1 & 0 & 0 & 0 & 0 \\
17 & 0 & 0 & 0 & 0 & 0 & 1 & 0 & 0 & 0 & 0 & 0 & 1 & 0 & 0 & 0 & 1 & 1 & 0 & 0 & 0 \\
18 & 0 & 0 & 0 & 0 & 0 & 0 & 0 & 0 & 1 & 0 & 1 & 0 & 0 & 0 & 0 & 1 & 1 & 1 & 0 & 0 \\
19 & 0 & 0 & 0 & 0 & 0 & 0 & 0 & 0 & 0 & 0 & 0 & 0 & 1 & 1 & 1 & 0 & 0 & 0 & 1 & 0 \\
20 & 1 & 0 & 0 & 0 & 0 & 1 & 0 & 0 & 0 & 0 & 0 & 1 & 0 & 0 & 0 & 1 & 0 & 0 & 0 & 1 \\
\hline
\end{tabular}


Table 5. Reachability Matrix of critical success factors

\begin{tabular}{|c|c|c|c|c|c|c|c|c|c|c|c|c|c|c|c|c|c|c|c|c|c|}
\hline $\begin{array}{c}\text { Factors } \\
(i / j)\end{array}$ & 1 & 2 & 3 & 4 & 5 & 6 & 7 & 8 & 9 & 10 & 11 & 12 & 13 & 14 & 15 & 16 & 17 & 18 & 19 & 20 & $\begin{array}{l}\text { Driver } \\
\text { power }\end{array}$ \\
\hline 1 & 1 & 1 & 1 & 1 & 1 & 1 & 1 & 1 & 0 & 1 & 1 & 1 & 0 & 0 & 0 & 1 & 1 & 0 & 0 & 0 & 13 \\
\hline 2 & 1 & 1 & 1 & 1 & 1 & 1 & 1 & 1 & 0 & 1 & 1 & 1 & 0 & 0 & 0 & 1 & 1 & 0 & 0 & 0 & 13 \\
\hline 4 & 1 & 1 & 1 & 1 & 1 & 1 & 1 & 1 & 0 & 1 & 1 & 1 & 0 & 0 & 0 & 1 & 1 & 0 & 0 & 0 & 13 \\
\hline 5 & 1 & 1 & 1 & 1 & 1 & 1 & 1 & 1 & 0 & 1 & 1 & 1 & 0 & 0 & 0 & 1 & 1 & 0 & 0 & 0 & 13 \\
\hline 6 & 1 & 1 & 1 & 1 & 1 & 1 & 1 & 1 & 0 & 1 & 1 & 1 & 0 & 0 & 0 & 1 & 1 & 0 & 0 & 0 & 13 \\
\hline 7 & 1 & 1 & 1 & 1 & 1 & 1 & 1 & 1 & 0 & 1 & 1 & 1 & 0 & 0 & 0 & 1 & 1 & 0 & 0 & 0 & 13 \\
\hline 8 & 1 & 1 & 1 & 1 & 1 & 1 & 1 & 1 & 0 & 1 & 1 & 1 & 0 & 0 & 0 & 1 & 1 & 0 & 0 & 0 & 13 \\
\hline 9 & 0 & 0 & 0 & 0 & 0 & 0 & 0 & 0 & 1 & 0 & 1 & 1 & 0 & 0 & 0 & 0 & 0 & 0 & 0 & 0 & 3 \\
\hline 10 & 0 & 0 & 0 & 0 & 0 & 0 & 0 & 0 & 0 & 1 & 0 & 0 & 0 & 0 & 0 & 0 & 0 & 0 & 0 & 0 & 1 \\
\hline 11 & 0 & 0 & 0 & 0 & 0 & 0 & 0 & 0 & 0 & 0 & 1 & 1 & 0 & 0 & 0 & 0 & 0 & 0 & 0 & 0 & 2 \\
\hline 12 & 0 & 0 & 0 & 0 & 0 & 0 & 0 & 0 & 0 & 0 & 1 & 1 & 0 & 0 & 0 & 0 & 0 & 0 & 0 & 0 & 2 \\
\hline 13 & 1 & 1 & 1 & 1 & 1 & 1 & 1 & 1 & 1 & 1 & 1 & 1 & 1 & 1 & 1 & 1 & 1 & 0 & 0 & 1 & 18 \\
\hline 14 & 1 & 1 & 1 & 1 & 1 & 1 & 1 & 1 & 1 & 1 & 1 & 1 & 0 & 1 & 1 & 1 & 1 & 0 & 0 & 1 & 17 \\
\hline 15 & 1 & 1 & 1 & 1 & 1 & 1 & 1 & 1 & 1 & 1 & 1 & 1 & 0 & 1 & 1 & 1 & 1 & 0 & 0 & 1 & 17 \\
\hline 16 & 0 & 0 & 0 & 0 & 0 & 0 & 0 & 0 & 0 & 0 & 0 & 0 & 0 & 0 & 0 & 1 & 0 & 0 & 0 & 0 & 1 \\
\hline 18 & 1 & 1 & 1 & 1 & 1 & 1 & 1 & 1 & 1 & 1 & 1 & 1 & 0 & 0 & 0 & 1 & 1 & 1 & 0 & 0 & 15 \\
\hline 19 & 1 & 1 & 1 & 1 & 1 & 1 & 1 & 1 & 1 & 1 & 1 & 1 & 1 & 1 & 1 & 1 & 1 & 0 & 1 & 1 & 19 \\
\hline 20 & 1 & 1 & 1 & 1 & 1 & 1 & 1 & 1 & 0 & 1 & 1 & 1 & 0 & 0 & 0 & 1 & 1 & 0 & 0 & 1 & 14 \\
\hline $\begin{array}{c}\text { Dependence } \\
\text { power }\end{array}$ & 15 & 15 & 15 & 15 & 15 & 15 & 15 & 15 & 6 & 16 & 18 & 18 & 2 & 4 & 4 & 16 & 15 & 1 & 1 & 5 & \\
\hline
\end{tabular}

Table 6. First iteration of Reachability Matrix

\begin{tabular}{|c|c|c|c|c|}
\hline Factor (Fi) & Reachability set: $R(\mathrm{Fi})$ & Antecedent set: $A(\mathrm{Fi})$ & Intersection $R(\mathrm{Fi}) \cap A(\mathrm{Fi})$ & Level \\
\hline 1 & $1 \sim 8,10,11,12,16,17$ & $1 \sim 8,13,14,15,17 \sim 20$ & $1 \sim 8,17$ & \\
\hline 2 & $1 \sim 8,10,11,12,16,17$ & $1 \sim 8,13,14,15,17 \sim 20$ & $1 \sim 8,17$ & \\
\hline 3 & $1 \sim 8,10,11,12,16,17$ & $1 \sim 8,13,14,15,17 \sim 20$ & $1 \sim 8,17$ & \\
\hline 4 & $1 \sim 8,10,11,12,16,17$ & $1 \sim 8,13,14,15,17 \sim 20$ & $1 \sim 8,17$ & \\
\hline 5 & $1 \sim 8,10,11,12,16,17$ & $1 \sim 8,13,14,15,17 \sim 20$ & $1 \sim 8,17$ & \\
\hline 6 & $1 \sim 8,10,11,12,16,17$ & $1 \sim 8,13,14,15,17 \sim 20$ & $1 \sim 8,17$ & \\
\hline 7 & $1 \sim 8,10,11,12,16,17$ & $1 \sim 8,13,14,15,17 \sim 20$ & $1 \sim 8,17$ & \\
\hline 8 & $1 \sim 8,10,11,12,16,17$ & $1 \sim 8,13,14,15,17 \sim 20$ & $1 \sim 8,17$ & \\
\hline 9 & $9,11,12$ & $9,13,14,15,18,19,20$ & 9 & \\
\hline 10 & 10 & $1 \sim 8,10,13,14,15,17 \sim 20$ & 10 & I \\
\hline 11 & 11,12 & $1 \sim 8,11 \sim 15,17 \sim 20$ & 11,12 & I \\
\hline 12 & 11,12 & $1 \sim 9,11 \sim 15,17 \sim 20$ & 11,12 & I \\
\hline 13 & $1 \sim 18,20$ & 13,19 & 13 & \\
\hline 14 & $1 \sim 12,14 \sim 17,20$ & $13,14,15,19$ & 14,15 & \\
\hline 15 & $1 \sim 12,14 \sim 17,20$ & $13,14,15,19$ & 14,15 & \\
\hline 16 & 16 & $1 \sim 8,13 \sim 20$ & 16 & I \\
\hline 17 & $1 \sim 8,10,11,12,16,17$ & $1 \sim 8,13,14,15,17 \sim 20$ & $1 \sim 8,17$ & \\
\hline 18 & $1 \sim 12,16,17,18$ & 18 & 18 & \\
\hline 19 & $1 \sim 17,19,20$ & 19 & 19 & \\
\hline 20 & $1 \sim 12,16,17,20$ & $13,14,15,19,20$ & 20 & \\
\hline
\end{tabular}

Table 7. Second iteration of Reachability Matrix

\begin{tabular}{ccccc}
\hline Factor $(\mathrm{Fi})$ & Reachability set: $R(\mathrm{Fi})$ & Antecedent set: $A(\mathrm{Fi})$ & Intersection $R(\mathrm{Fi}) \cap A(\mathrm{Fi})$ & Level \\
\hline 1 & $1 \sim 8,17$ & $1 \sim 8,13,14,15,17 \sim 20$ & $1 \sim 8,17$ & $1 \sim 8,17$ \\
2 & $1 \sim 8,17$ & $1 \sim 8,13,14,15,17 \sim 20$ & $1 \sim 8,17$ & II \\
3 & $1 \sim 8,17$ & $1 \sim 8,13,14,15,17 \sim 20$ & $1 \sim 8,17$ & II \\
4 & $1 \sim 8,17$ & $1 \sim 8,13,14,15,17 \sim 20$ & $1 \sim 8,17$ & II \\
5 & $1 \sim 8,17$ & $1 \sim 8,13,14,15,17 \sim 20$ & $1 \sim 8,17$ & II \\
6 & $1 \sim 8,17$ & $1 \sim 8,13,14,15,17 \sim 20$ & $1 \sim 8,17$ & II \\
7 & $1 \sim 8,17$ & $1 \sim 8,13,14,15,17 \sim 20$ & $1 \sim 8,17$ & II \\
8 & $1 \sim 8,17$ & $1 \sim 8,13,14,15,17 \sim 20$ & 13 & II \\
9 & 9 & $9,13,14,15,18,19,20$ & 14,15 & \\
13 & $1 \sim 10,14,15,16,18,21$ & 13,19 & 14,15 & \\
14 & $1 \sim 10,15,16,18,21$ & $13,14,15,19$ & $1 \sim 8,17$ & \\
15 & $1 \sim 10,15,16,18,21$ & $13,14,15,19$ & 18 & \\
17 & $1 \sim 9,18$ & $1 \sim 8,13,14,15,17 \sim 20$ & 18 & 19 \\
\end{tabular}


Table 8. Last iteration (5th) of Reachability Matrix

\begin{tabular}{ccccc}
\hline Factor $(\mathrm{Fi})$ & Reachability set: $R(\mathrm{Fi})$ & Antecedent set: $A(\mathrm{Fi})$ & Intersection $R(\mathrm{Fi}) \cap A(\mathrm{Fi})$ & $\mathrm{Level}$ \\
\hline 13 & 13 & 13,19 & 13 & $\mathrm{~V}$ \\
19 & 13 & 13,19 & 19 & $\mathrm{~V}$ \\
\hline
\end{tabular}

all the factors were exhausted and their respective levels obtained. The result of the last iteration (5th) is shown in Table 8.

\subsection{Mapping relationships between factors}

A directed graph (digraph), where the factors correspond to the nodes of the network, meanwhile, the interrelationships between any two factors are denoted as directional arrows (links) representing the features of the relationships (leads to or has no influence on), will be able to pictorially interpret the contextual relationships between each two of these CSFs and their hierarchies (Lyer, Sagheer 2010). The factors which were moved out during the first iteration (Table 6) appear at Level I and were placed at the top of the hierarchy. Consequently, factors $10,11,12$, and 16 appear at the top. Thereafter, factors 1 9 and 17 which were moved out during the second iteration appear at Level II. Similarly, the hierarchical digraph of CSFs of innovation in China's construction projects obtained from ISM is achieved and shown in Figure 2.

From the digraph, it can be noticed that external support in terms of supportive regional and national policies for innovation can generate owners' involvement and leadership. Therefore, making innovation a priority for the whole nation is necessary. In the innovation network of construction projects, owners play significant parts. They not only act as the main financially supportive parties but also as the ones that demand innovation most and apply new technologies in accordance with the clear

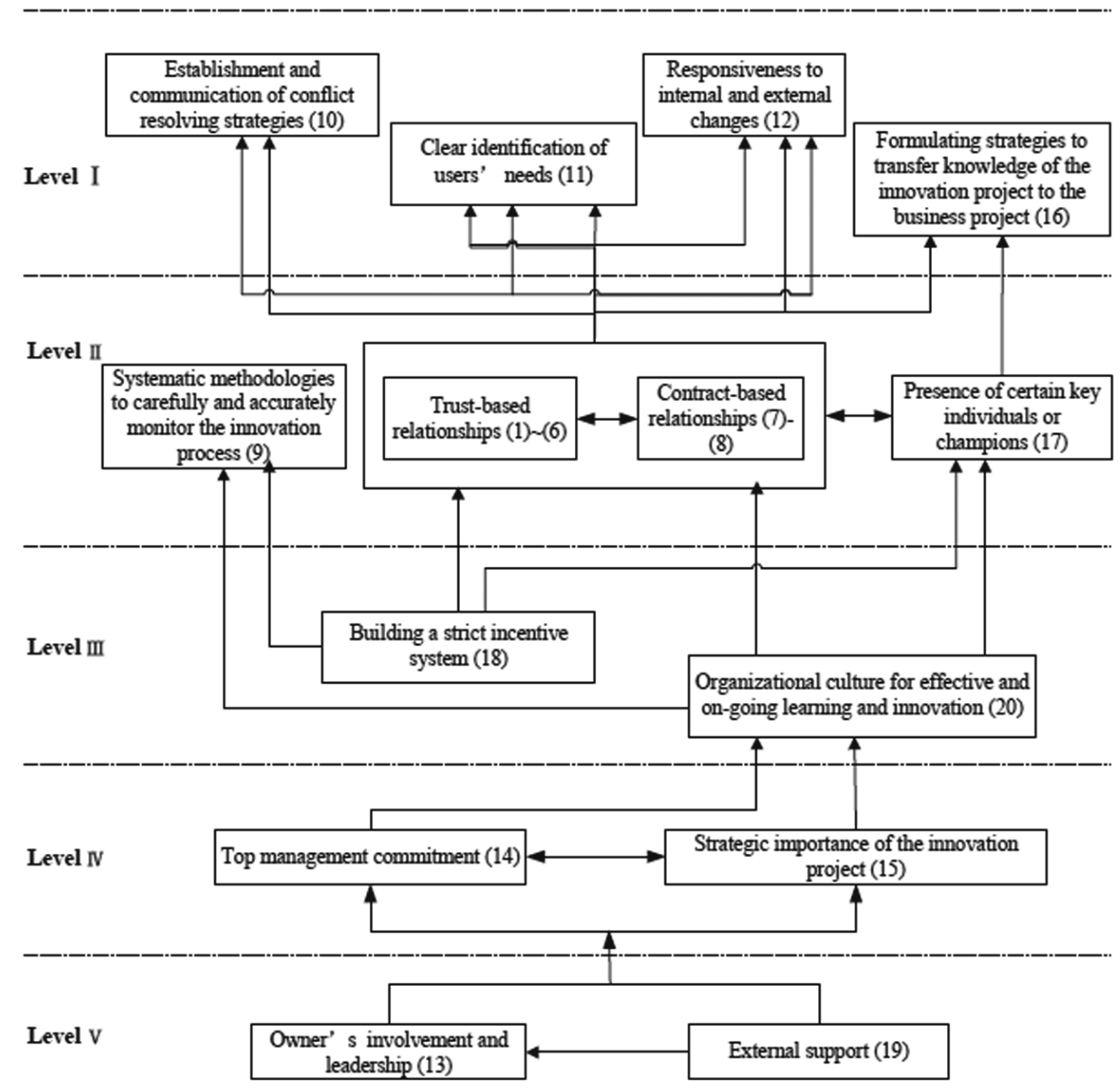

Fig. 2. Diagraph of CSFs for innovation in China's construction projects 
identification of the users' needs and market research (Van der Panne et al. 2003). External support as well as the owner's involvement and leadership can pressure the top management into commitment to ensure the strategic importance of the innovation project. In addition, the strategic importance of the innovation project can also guarantee the support from top management. Through the interaction of these two factors, consequently, the organizational culture of the participants in the network will become more and more suitable for inter-organizational learning and cooperation (Tidd, Bessant 2011; Skibniewski, Zavadskas 2013). A strict incentive system should be operated to reward successful innovation initiatives and to penalize failing ones with budget cuts (Kim et al. 2009). As shown in the structured diagraph, organizational culture for learning and cooperation as well as building a strict incentive system can accelerate partnership construction, promote the presence of integration champions as well as induce the systematic methodologies to carefully monitor the innovation process. Furthermore, the presence of integration champions and harmonious partnering relationships will ensure the capable innovation team, which possesses sufficient capabilities to solve different problems occurred during the innovation process including identifying users' needs, responding to changes, resolving conflicts and transferring knowledge of the innovation project to the business project. Except for that, systematic methodologies to carefully monitor the innovation projects should be formed up due to the fact that innovation outcomes are usually difficult to evaluate.

\section{Degrees of relationships between CSFs}

MICMAC was implemented to identify the degrees of relationships between CSFs. The key concepts of MICMAC are driver power and dependence power, which can be gained through $R$ (Table 5). The driver power of each factor is the summation of $1 \mathrm{~s}$ in the row that corresponds to the factor, while the dependence power of each factor is the summation of $1 \mathrm{~s}$ in the corresponding column. According to the driver power and dependence power of each factor, MICMAC partitions all the factors into four clusters in terms of autonomous, dependent, linkage, and independent groups (Fig. 3).

It can be found from Figure 3 that factors belonging to the autonomous group have a weak driver power and a weak dependence power. In the present study, only factor 9 is located in this cluster. The dependent cluster includes factor 10,11, 12, and 16 appearing at the top of the ISM hierarchy. According to the weak driver powers but strong dependency of these factors, due care must be taken by the managers to check the other factors to insure the results of these four elements.

The third group, called linkage group, is composed of factors $1-8$, and 17 . Any change occurring to the factor of this group will have an effect on other factors in the system because each factor of this group has a strong driver power and a strong dependence power. The suc-

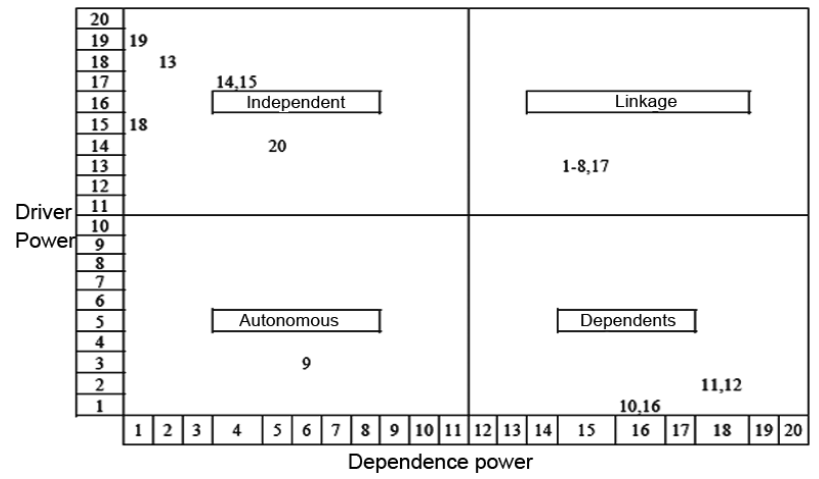

Fig. 3. Classification of CSFs

cess of innovation in construction projects is the result of the combined efforts of numerous participants. The establishment of harmonious partnerships can help balance partners' expectations, and coordinate their efforts for pursuing the common target of innovation. Once the parties have a common vision on cooperation, a team is then established (Cheng, Li 2002; Skibniewski, Zavadskas 2013). Trust-based partnerships depict that the selection of partners of innovation projects should not only check out partner firms' reliability at the project level; their intentions to rerun a cooperative innovation project team at a strategic level should also not be ignored. As to the execution level, the presence of integration champions is the catalyst of synchronized innovations in the network. Currently, integration champions who orchestrate collaboration will be more important to innovation in China's construction industry, because construction products become more and more complex, which demands sophisticated new technologies and more specialists as Nam and Tatum (1992) claimed.

Independent group consists of factors $13,14,15$, 18,19 , and 20 with strong driving powers but weak dependence powers. Especially, factors 13, 14, 15, 19 each have a driver power of 17 or more, as perceived by experts. These factors appearing at the bottom two levels of the digraph derived from ISM act as the root source of critical success factors for the innovation in China's construction projects. According to the law of vital few and trivial many, $80 \%$ of effects come from $20 \%$ of the causes for many events, controlling these factors should give maximum benefit (Xu et al. 2010). Furthermore, factor 19 (external support), which beyond the boundaries of innovation projects networks, has the highest driver power, which means achievement of this factor will very likely impact the success of innovation in China's construction projects.

\section{Conclusions}

This paper identifies 20 CSFs for innovation in China's construction projects through literature review, a case study and expert interviews. ISM was used to hierarchically structure the CSFs depending on the interrelation- 
ships between the factors perceived from experts who possess rich experience in the field of innovation in construction projects. To extend and complement the result that users can draw from the digraph derived from ISM, this paper applied MICMAC method to measure the degrees of relationships between CSFs through analyzing the driver and dependence power of each factor. Along with MICMAC, ISM establishes a hierarchical order for prioritization and consequent action for the decisionmaking process by providing the decision makers with structural clarity.

The findings show that most of the CSFs (19 out of 20) have strong interrelationships. In the implementation of projects, extensive efforts should be focused on independent and linkage clusters, which consist of factors with strong driver powers. In particular, factors 13, 14, 15 , and 19 are located in the independent cluster with driver powers above 17 and they also appear at the bottom two levels of the digraph derived from ISM. The vital CSFs in innovation projects for construction projects, control of which should give maximum benefit, are given in this paper as factors 13 (owner's involvement and leadership), 14 (top management commitment), 15 (strategic importance of the innovation project), 19 (external support). More specifically, to derive high performance from construction innovation, the project owner should be involved in key aspects of the project execution, and the owner's involvement should lead the whole innovation network to give strategic importance to innovation projects. Commitment on the part of the owner's and contractors' top management to provide necessary resources and authority for project success from the project's inception onwards is essential for success. Given that factor 20 (external support) owns the highest driver power, government bodies whose mission is financial and infrastructure support for innovation should focus on national initiatives to endorse construction innovation.

Comprehensive research on innovation in China's construction projects is still in its inception. Results presented in this paper conceptualize for participants of construction projects their formulation of a strategy to manage their own innovation initiatives. However, as CSFs vary from project to project, further research concerning CSFs should consider the impact of delivery methods adopted by a particular construction project. Given that the construction projects consist of various project types, the single project type of our case study can make the generalizability of the findings doubtful. Besides, the fairly small sample size of experts and the limited number of case study project render the results obtained in this study more indicative rather than representative. Therefore, larger number of experts and case study projects involved are highly needed, which would strongly increase the reliability and validity of the findings.

\section{Acknowledgements}

Special gratitude is extended to all who have kindly participated in the questionnaire survey of construction industry experts reported in this paper. The authors would like to thank the reviewers for their careful evaluation and thoughtful comments. The work described in this paper was supported by the National Science Foundation of China (Grant No. 71273283/G0307), the Doctoral Program of the Ministry of Education of China (Grant No. 20130162110022), the Soft Science Research Project of Hunan Province (Grant No. 2014ZK3079) and the China Scholarship Council (Grant No. 201206370110).

\section{References}

Akbiyikli, R.; Eaton, D.; Dikmen, S. U. 2012. Achieving sustainable construction within private finance initiative (PFI) road projects in the UK, Technological and Economic Development of Economy 18(2): 207-229. http://dx.doi.org/10.3846/20294913.2012.677586

Allen Consulting Group Pty Ltd. 2010. Productivity in the building networks: assessing the impacts of building information models. Report to the Built Environment Innovation and Industry Council. Sydney, Australia. 98 p.

Azevedo, S.; Carvalho, H.; Cruz-Machado, V. 2013. Using interpretive structural modelling to identify and rank performance measures: an application in the automotive supply chain, Baltic Journal of Management 8(2): 208-230. http://dx.doi.org/10.1108/17465261311310027

Barlow, J.; Jashapara, A. 1998. Organizational learning and inter-firm "partnering" in the UK construction industry, Learning Organization 5(2): 86-98. http://dx.doi.org/10.1108/09696479810212051

Blayse, A. M.; Manley, K. 2004. Key influences on construction innovation, Construction Innovation: Information, Process, Management 4(3): 143-154.

Blindenbach-Driessen, F.; van den Ende, J. 2006. Innovation in project-based firms: the context dependency of success factors, Research Policy 35(4): 545-561. http://dx.doi.org/10.1016/j.respol.2006.02.005

Bosch-Sijtsema, P. M.; Postma, T. J. B. M. 2009. Cooperative innovation projects: capabilities and governance mechanisms, Journal of Product Innovation Management 26(1): 5870. http://dx.doi.org/10.1111/j.1540-5885.2009.00334.x

Bossink, B. A. 2004. Managing drivers of innovation in construction networks, Journal of Construction Engineering and Management 130(3): 337-345.

http://dx.doi.org/10.1061/(ASCE)0733-9364(2004)130:3(337)

Bröchner, J.; Badenfelt, U. 2011. Changes and change management in construction and IT projects, Automation in Construction 20(7): 767-775. http://dx.doi.org/10.1016/j.autcon.2011.01.001

Chan, A. P.; Lam, P. T.; Chan, D. W.; Cheung, E.; Ke, Y. 2010. Critical success factors for PPPs in infrastructure developments: Chinese perspective, Journal of Construction Engineering and Management 136(5): 484-494. http://dx.doi.org/10.1061/(ASCE)CO.1943-7862.0000152

Cheng, E. W.; Li, H.; Love, P. E. D. 2000. Establishment of critical success factors for construction partnering, Journal of Management in Engineering 16(2): 84-92. http://dx.doi.org/10.1061/(ASCE)0742-597X(2000)16:2(84)

Cheng, E. W.; Li, H. 2002. Construction partnering process and associated critical success factors: quantitative investigation, Journal of Management in Engineering 18(4): 194-202.

http://dx.doi.org/10.1061/(ASCE)0742-597X(2002)18:4(194) 
Cheng, M. Y.; Tsai, H. C.; Sudjono, E. 2012. Evolutionary fuzzy hybrid neural network for dynamic project success assessment in construction industry, Automation in Construction 21: 46-51. http://dx.doi.org/10.1016/j.autcon.2011.05.011

Chen, W. T.; Chen, T. T. 2007. Critical success factors for construction partnering in Taiwan, International Journal of Project Management 25(5): 475-484. http://dx.doi.org/10.1016/j.ijproman.2006.12.003

Dubois, A.; Gadde, L. E. 2002. The construction industry as a loosely coupled system: implications for productivity and innovation, Construction Management and Economics 20(7): 621-631. http://dx.doi.org/10.1080/01446190210163543

Forcada, N.; Fuertes, A.; Gangolells, M.; Casals, M.; Macarulla, M. 2013. Knowledge management perceptions in construction and design companies, Automation in Construction 29: 83-91.

http://dx.doi.org/10.1016/j.autcon.2012.09.001

Freeman, C.; Soete, L.1997. The economics of industrial innovation. London: Routledge. $256 \mathrm{p}$.

Gann, D. M.; Salter, A. J. 2000. Innovation in project-based, service-enhanced firms: the construction of complex products and systems, Research Policy 29(7): 955-972. http://dx.doi.org/10.1016/S0048-7333(00)00114-1

Ghoddousi, P.; Hosseini, M. R. 2012. A survey of the factors affecting the productivity of construction projects in Iran, Technological and Economic Development of Economy 18(1): 99-116.

http://dx.doi.org/10.3846/20294913.2012.661203

Gudienè, N.; Banaitis, A.; Banaitienè, N. 2013. Evaluation of critical success factors for construction projects - an empirical study in Lithuania, International Journal of Strategic Property Management 17(1): 21-31. http://dx.doi.org/10.3846/1648715X.2013.787128

Guion, L. A.; Diehl, D. C.; McDonald, D. 2011. Triangulation: establishing the validity of qualitative studies. University of Florida, USA. 3 p.

Hartmann, T.; Fischer, M. 2008. Applications of BIM and hurdles for widespread adoption of BIM. Stanford University, Stanford, CA. 20 p.

Holmen, E.; Pedersen, A. C.; Torvatn, T. 2005. Building relationships for technological innovation, Journal of Business Research 58(9): 1240-1250.

http://dx.doi.org/10.1016/j.jbusres.2003.10.010

Jones, M.; Saad, M. 2003. Managing innovation in construction. London: Thomas Telford. $314 \mathrm{p}$.

Kamara, J. M.; Anumba, C. J.; Carrillo, P. M. 2002. A CLEVER approach to selecting a knowledge management strategy, International Journal of Project Management 20(3): 205211. http://dx.doi.org/10.1016/S0263-7863(01)00070-9

Katz, R. (Ed.). 2004. The human side of managing technological innovation: a collection of readings. Vol. 2. New York: Oxford University Press. $752 \mathrm{p}$.

Kim, C.; Kim, H.; Han, S. H.; Kim, C.; Kim, M. K.; Park, S. H. 2009. Developing a technology roadmap for construction R\&D through interdisciplinary research efforts, Automation in Construction 18(3): 330-337. http://dx.doi.org/10.1016/j.autcon.2008.09.008

Kulatunga, U.; Amaratunga, R. D. G.; Haigh, R. P. 2006. Construction innovation: a literature review on current research [online], [cited 10 July 2014]. Available from Internet:

http://usir.salford.ac.uk/9886/1/205 Kulatunga KJ et al CONSTRUCTION INNOVATION A LITERATURE-

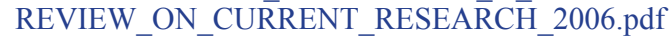

Lee, S. K.; Yu, J. H. 2012. Success model of project management information system in construction, Automation in Construction 25: 82-93.

http://dx.doi.org/10.1016/j.autcon.2012.04.015
Lendaris, G. G. 1980. Structural modeling a tutorial guide, IEEE Transactions on Systems, Man and Cybernetics 10(12): 807-840.

Linstone, H. A.; Lendaris, G. G.; Rogers, S. D.; Wakeland, W.; Williams, M. 1979. The use of structural modeling for technology assessment, Technological Forecasting and Social Change 14(4): 291-327.

http://dx.doi.org/10.1016/0040-1625(79)90032-5

Lyer, K. C.; Sagheer, M. 2010. Hierarchical structuring of PPP risks using interpretative structural modeling, Journal of Construction Engineering and Management 136(2): 151159.

http://dx.doi.org/10.1061/(ASCE)CO.1943-7862.0000127

Mandal, A.; Deshmukh, S. G. 1994. Vendor selection using interpretive structural modeling (ISM), International Journal of Operations and Production Management 14(6): 52-59. http://dx.doi.org/10.1108/01443579410062086

Meng, X. 2013. Change in UK construction: moving toward supply chain collaboration, Journal of Civil Engineering and Management 19(3): 422-432.

http://dx.doi.org/10.3846/13923730.2012.760479

Miozzo, M.; Dewick, P. 2004. Networks and innovaton in European construction: benefits from inter-organizational cooperation in a fragmented industry, International Journal of Technology Management 27(1): 68-92. http://dx.doi.org/10.1504/IJTM.2004.003882

Nam, C. H.; Tatum, C. B. 1992. Noncontractual methods of integration on construction projects, Journal of Construction Engineering and Management 118(2): 385-398.

http://dx.doi.org/10.1061/(ASCE)0733-9364(1992)118:2(385)

Nam, C. H.; Tatum, C. B. 1997. Leaders and champions for construction innovation, Construction Management and Economics 15(3): 259-270.

http://dx.doi.org/10.1080/014461997372999

Ozorhon, B. 2013. Analysis of construction innovation process at project level, Journal of Management in Engineering 29(4): 455-463.

http://dx.doi.org/10.1061/(ASCE)ME.1943-5479.0000157

Ozorhon, B.; Abbott, C.; Aouad, G. 2014. Integration and leadership as enablers of innovation in construction: a case study, Journal of Management in Engineering 30(2): 256-263.

http://dx.doi.org/10.1061/(ASCE)ME.1943-5479.0000204

Park, Y.; Son, H.; Kim, C. 2012. Investigating the determinants of construction professionals' acceptance of web-based training: an extension of the technology acceptance model, Automation in Construction 22: 377-386. http://dx.doi.org/10.1016/j.autcon.2011.09.016

Pinto, J. K.; Covin, J. G. 1989. Critical factors in project implementation: a comparison of construction and R\&D projects, Technovation 9(1): 49-62. http://dx.doi.org/10.1016/0166-4972(89)90040-0

Radziszewska-Zielina, E. 2010. Methods for selecting the best partner construction enterprise in terms of partnering relations, Journal of Civil Engineering and Management 16(4): 510-520. http://dx.doi.org/10.3846/jcem.2010.57

Rothwell, R. 1992. Successful industrial innovation: critical factors for the 1990s, R\&D Management 22(3): 221-240. http://dx.doi.org/10.1111/j.1467-9310.1992.tb00812.x

Sagheer, S.; Yadav, S. S.; Deshmukh, S. G. 2009. An application of interpretative structural modeling of the compliance to food standards, International Journal of Productivity and Performance Management 58(2): 136-159. http://dx.doi.org/10.1108/17410400910928734

Serpell, A.; Kort, J.; Vera, S. 2013. Awareness, actions, drivers and barriers of sustainable construction in Chile, Technological and Economic Development of Economy 19(2): 272-288.

http://dx.doi.org/10.3846/20294913.2013.798597 
Skibniewski, M. J.; Zavadskas, E. K. 2013. Technology development in construction: a continuum from distant past into the future, Journal of Civil Engineering and Management 19(1): 136-147. http://dx.doi.org/10.3846/13923730.2012.756060

Slaughter, E. S. 1998. Models of construction innovation, Journal of Construction Engineering and Management 124(3): 226-231.

http://dx.doi.org/10.1061/(ASCE)0733-9364(1998)124:3(226)

Slaughter, E. S. 2000. Implementation of construction innovations, Building Research and Information 28(1): 2-17. http://dx.doi.org/10.1080/096132100369055

Thakkar, J.; Kanda, A.; Deshmukh, S. G. 2008. Interpretive structural modeling (ISM) of IT-enablers for Indian manufacturing SMEs, Information Management \& Computer Security 16(2): 113-136. http://dx.doi.org/10.1108/09685220810879609

Tidd, J.; Bessant, J. 2011. Managing innovation: integrating technological, market and organizational change. New York: John Wiley \& Sons. 638 p.

Van der Panne, G.; Van Beers, C.; Kleinknecht, A. 2003. Success and failure of innovation: a literature review, International Journal of Innovation Management 7: 309-338. http://dx.doi.org/10.1142/S1363919603000830

Veshosky, D. 1998. Managing innovation information in engineering and construction firms, Journal of Management in Engineering 14(1): 58-66. http://dx.doi.org/10.1061/(ASCE)0742-597X(1998)14:1(58)

Wan, D.; Ong, C. H.; Lee, F. 2005. Determinants of firm innovation in Singapore, Technovation 25(3): 261-268. http://dx.doi.org/10.1016/S0166-4972(03)00096-8
Widén, K.; Olander, S.; Atkin, B. 2014. Links between successful innovation diffusion and stakeholder engagement, Journal of Management in Engineering 30(5), 04014018. http://dx.doi.org/10.1061/(ASCE)ME.1943-5479.0000214

Winch, G. M. 2003. How innovative is construction? Comparing aggregated data on construction innovation and other sectors - a case of apples and pears, Construction Management and Economics 21(6): 651-654. http://dx.doi.org/10.1080/0144619032000113708

Xu, Y.; Yeung, J. F.; Chan, A. P.; Chan, D. W.; Wang, S. Q.; Ke, Y. J. 2010. Developing a risk assessment model for PPP projects in China - a fuzzy synthetic evaluation approach, Automation in Construction 19(7): 929-943. http://dx.doi.org/10.1016/j.autcon.2010.06.006

Xue, X.; Shen, Q.; Ren, Z. 2010. Critical review of collaborative working in construction projects: business environment and human behaviors, Journal of Management in Engineering 26(4): 196-208. http://dx.doi.org/10.1061/(ASCE)ME.1943-5479.0000025

Yong, Y. C.; Mustaffa, N. E. 2013. Critical success factors for Malaysian construction projects: an empirical assessment, Construction Management and Economics 31(9): 959978. http://dx.doi.org/10.1080/01446193.2013.828843

Yong, Y. C.; Mustaffa, N. E. 2012. Analysis of factors critical to construction project success in Malaysia, Engineering, Construction and Architectural Management 19(5): 543556. http://dx.doi.org/10.1108/09699981211259612

Zavadskas, E. K.; Turskis, Z.; Tamošaitiene, J. 2010. Risk assessment of construction projects, Journal of Civil Engineering and Management 16(1): 33-46. http://dx.doi.org/10.3846/jcem.2010.03

\section{Appendix \\ Protocol for experts}

The following table (Section B) is intended to register the professionals' perception about the interrelationships between CSFs identified in this paper.

Section A: Background Information

A1. Name of the institution to which you belong:

A2. Your job title:

A3. Your research interests (if you are from academics):

A4. Your role in the construction industry:

a. Owner; b. Contractor; c. Supplier; d. Designer; f. Other

A5. How many years have you been involved in the practice/research of innovation in construction project?

\section{Section B: Pairwise Comparison}

Please fill in the table according the following rules:

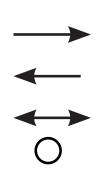

factor $\mathrm{i}$ leads to factor $\mathrm{j}$ factor $\mathrm{j}$ leads to factor $\mathrm{i}$ factor $\mathrm{i}$ and factor $\mathrm{j}$ help to achieve each other factor $i$ and factor $j$ are unrelated 


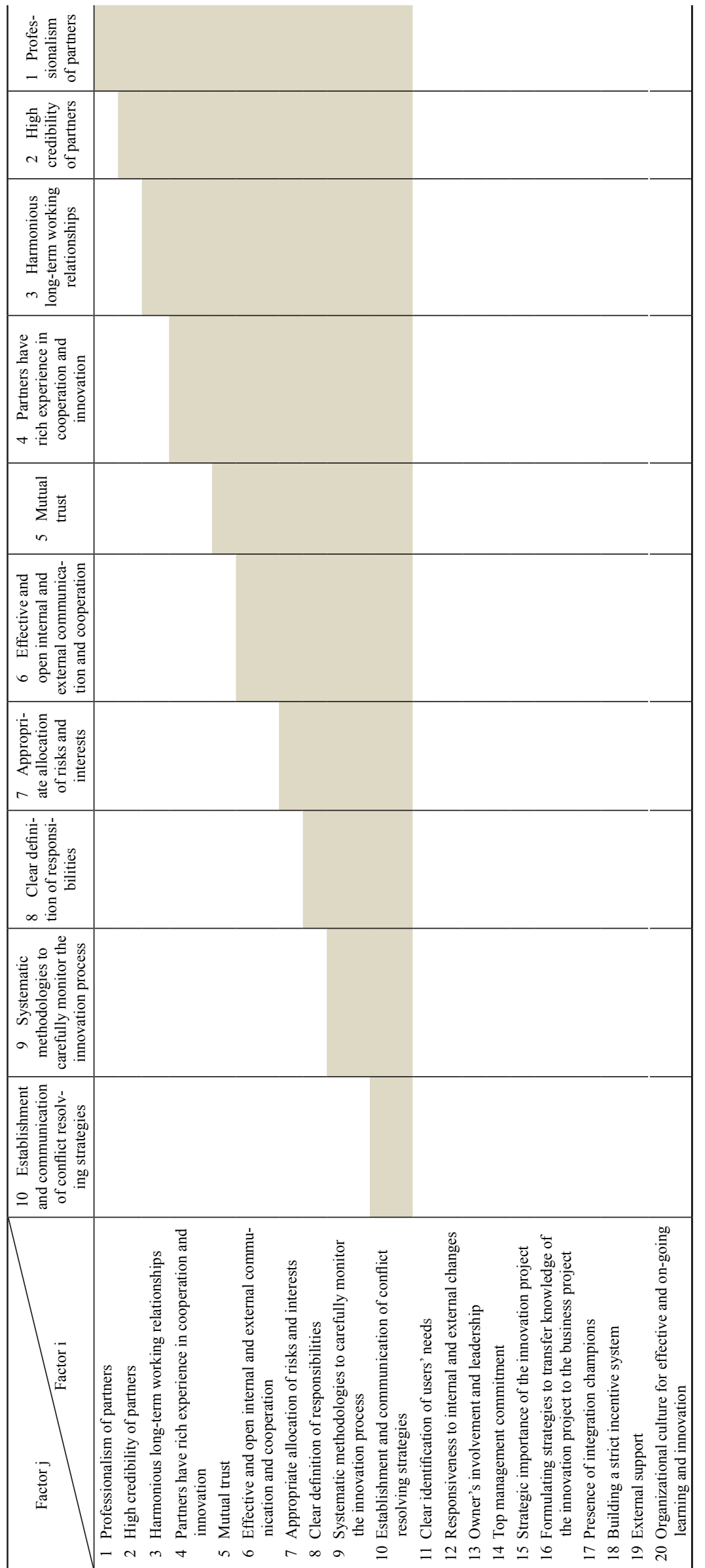

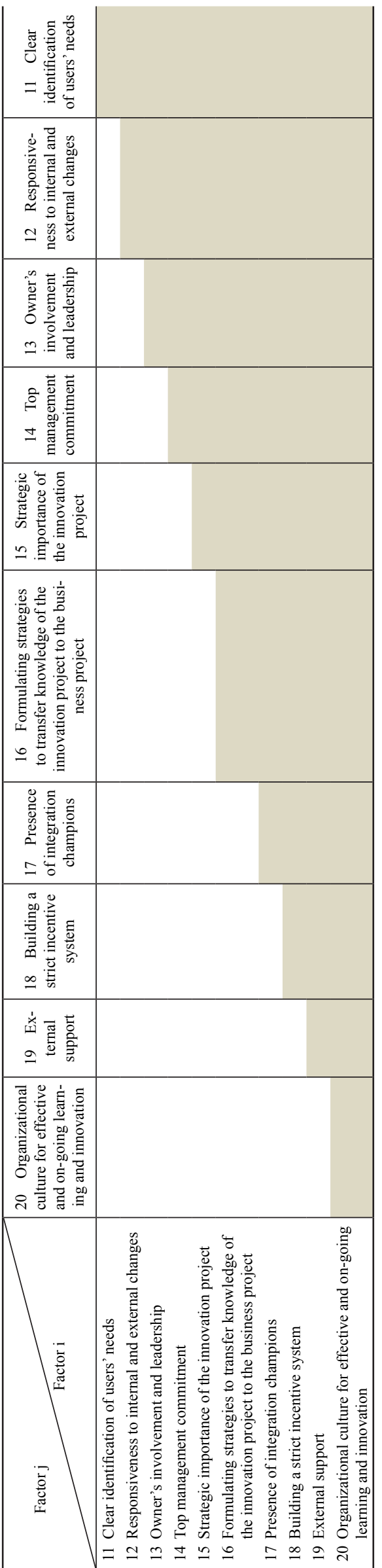


Hui LIU. PhD candidate of Civil Engineering Planning and Management at Central South University, Changsha, China. Joint-PhD student of Construction Engineering and Project Management at the University of Maryland (College Park), USA. Research interests mainly include management of construction innovation and implementation of advanced technologies in construction projects.

Miroslaw J. SKIBNIEWSKI. Professor of Construction Engineering and Project Management at the University of Maryland (College Park), USA. A past winner of the U.S. National Science Foundation Presidential Young Investigator Award, the Walter L. Huber Research Prize from the American Society of Civil Engineers and a foreign member of the Russian Academy of Engineering. A holder of an honorary doctorate form Vilnius Gediminas Technical University in Lithuania. An author or co-author of over 200 technical publications. Research interests include automation and information technology issues related to construction project engineering and management.

Mengjun WANG. Professor of Civil Engineering management at Central South Univeristy, Changshga, China. Director of Engineering Management Research Center at Central South Univeristy. Author or co-author of over 100 scholarly papers and a number of monographs on construction management. Research interests include management of construction innovation, construction technology and management, and construction economics. 